DOI 10.37882/2223-2982.2020.07.10

\title{
ТЕОРЕТИЧЕСКИЕ ОСНОВЫ ЦИФРОВИЗАЦИИ В ПРОФЕССИОНАЛЬНОМ ОБРАЗОВАНИИ
}

\section{THEORIES OF DIGITALIZATION IN VOCATIONAL EDUCATION}

E. Egorova

Summary: The article devotes to the urgent problem of the introduction and using the digital technologies in the educational process, namely the disclosure of the essence and determination of the prerequisites for using digital technologies in professional education in the context of the development of the global trend of society's digital transformation. The author defines the role of digitalization of education in the learning process. The article substantiates the need of application the capabilities of digital technology in the training of specialists as the main link in the formation and implementation of human capital. The aim of the article is to analyze the modern understanding of the pedagogical phenomenon of digitalization of education and to identify the possibilities of digital technologies in the framework of the educational process.

The conduction of the research work was under the methods of scientific analysis of the phenomenon under study, namely: a review of modern analytical sources that describe the phenomenon of digitalization of education and digital technologies. Also as a research material the author used regulatory documents defining the priority of development of the educational system in the Russian Federation.

The result of the study is the possibility of introducing such a multifaceted phenomenon as digitalization of education, which covers all spheres of human life, also the justification and the use of digital technologies in the educational process in order to successfully socialize in the emerging digital economy and society. The results of the study are to apply them in the field of vocational education in the new conditions.

Keywords: digitalization, professional education, digitalization of education, educational process, teaching methods, digital technology, online courses, submission of information.
Егорова Елена Михайловна

к.n.н., преподаватель, Колледж инфраструктурных технологий ФГАОУ ВО «Северо-Восточный федеральный университет им. М.К. Аммосова», г. Якутск

Elena-sakha@mail.ru

Аннотация: (татья посвящена актуальной проблеме внедрения и использования цифровых технологий в образовательный процесс, а именно раскрытию сущности и определению предпосылок использования цифровых технологий в профессиональном образовании в контексте развития глобального тренда цифровой трансформации общества. Автором определена роль цифровизации образования в процессе обучения. В статье обоснована необходимость применения возможностей цифровых технологий в обучении специалистов как основного звена формирования и реализации человеческого капитала. Целью статьи является анализ современного понимания педагогического феномена цифровизации образования и выявление возможности цифровых технологий в рамках образовательного процесса.

Исследование проводилось методами научного анализа исследуемого явления, а именно: обзор современных аналитических источников, описывающих феномен цифровизации образования и цифровых технологий. Также в качестве исследовательского материала послужили: нормативно-правовые документы, определяющие приоритетное развитие системы образования в РФ.

В результате исследования можно сделать вывод, что обоснована в0зможность внедрения такого многогранного феномена как цифровизация образования, который охватывает все сферы жизнедеятельности человека и рассмотрено применение цифровых технологий в образовательном процессе с тем, чтобы успешно социализироваться в формирующуюся цифровую экономику и общество. Результаты исследования могут быть применены В сфере профессионального образования в новых условиях.

Ключевые слова: цифровизация, профессиональное образование, цифровизация образования, образовательный процесс, методы обучения, цифровые технологии, онлайн курсы, подача информации.

Традиционное обучение упрощает способность студентов постигать основные дисциплины и препятствует их пониманию структуры и функции предмета, делает студентов пассивными получателями знаний. Таким путем трудно достигать образовательной цели в современных условиях. Мультимедийное обеспечение курса изучаемых дисциплин в системе среднего профессионального образования (СПО) может активизировать взгляды студентов; визуальное и яркое мультимедийное обеспечение учебного курса позволяет воспринимать знания разными способами (визуально, аудиально и т.п.).

Важную роль играет использование инновационных телекоммуникационных технологий и сети Интернет в подготовке специалистов технического профиля, так как 
без глубоких знаний по дисциплинам профессиональной компетентности в этой области достичь крайне трудно. Поэтому особое значение в системе профессионального образования приобретает вопрос, как обеспечить учебный процесс соответствующими информационными средствами, методами и учебными программами, чтобы образовательная организация, преподаватель и система повышения квалификации преподавателей отвечала современным глобальным и национальным вызовам и предоставляла современную поддержку в сфере цифровых технологий, развивала и формировала цифровые компетенции.

Значимость данной проблемы определена тем, что в современных условиях система российского образования должна интегрироваться в цифровую экономику. Поэтому требования к переходу к цифровизации профессионального образования на фоне повышения уровня компетентности во многих областях определяет требования к подготовке современных специалистов. Актуальность данной статьи обусловлена преодолением традиционной системы обучения различными ресурсами цифрового формата, в особенности технологиями обучения.

В связи с этим в 2016 г. был принят Приоритетный проект «Современная цифровая образовательная среда в Российской Федерации», который утвержден Правительством Российской Федерации. Представленный документ предполагает «модернизировать систему образования и профессиональной подготовки, привести образовательные программы в соответствие с нуждами цифровой экономики, широко внедрить цифровые инструменты учебной деятельности и целостно включить их в информационную среду, обеспечить возможность обучения граждан по индивидуальному учебному плану в течение всей жизни - в любое время и в любом месте» [4].

Также Правительством РФ 28 июля 2017 года была утверждена государственная программа «Цифровая экономика», которая дала толчок к развитию и внедрении термина «цифровизация» в российском образовании. Сегодня цифровые технологии становятся необходимой составляющей всех сфер жизнеобеспечения человека. Также цифровая экономика выступает для профессионального образования и обучения одним из средств получения знаний и формирования компетенций у обучающихся.

Следует отметить, что на данном этапе анализа термина «цифровизация», существует достаточно много разных определений. На анализе литературы по заданной теме исследования мы выяснили, что:
Цифровизация - это:

- новая социальная ситуация - «цифрового разрыва», «цифрового гражданства», «цифровой социализации»;

- цифровизация - это объективный процесс вытеснения всего аналогового из технологии, экономики, культуры;

- цифровая реальность «оцифровывает» и нас, накапливает наши цифровые следы», опережая не только вычислительную технику, но и наше воображение [16].

Энциклопедия «Викисловарь» объясняет семантический смысл термина «цифровизация» как «цифровой способ связи, записи, передачи данных с помощью цифровых устройств» [4]. А. Марей трактует цифровизацию как «изменение парадигмы общения и взаимодействия друг с другом и социумом» [15]. Е.Л. Вартанова, А.В. Вырковский, М.И. Макеенко, С.С. Смирнов уточняют содержание этого понятия: «...это не только перевод информации в цифровую форму, а комплексное решение инфраструктурного, управленческого, поведенческого, культурного характера» [7, с. 17].

В современных условиях перехода к цифровой экономике, к цифровому обществу можно с уверенностью сказать, что цифровизация прочно внедряется в образовательный процесс.

В своих работах Т.В. Никулина, В.Б. Стариченко отмечают, что «в образовании цифровизация направлена на обеспечение непрерывности процесса обучения, life-long-learning - обучение в течение жизни, а также его индивидуализации на основе advanced learningtechnologies - технологий продвинутого обучения» [18, c. 107].

Термин «цифровизация» (от англ.«didgital» цифровой) относительно системы образования можно понимать как комплексную методологию преобразований в учебном процессе, направленную на совершенствование гибкости, приспособленности к реалиям и вызовам современного общества, и способствующую формированию конкурентоспособных профессионалов, адаптированных к «цифровому миру» [17].

То есть под самой структурой цифровизации в данном контексте мы понимаем некий набор средств, технологий, направленных на повышение результативности, качества профессионального образования, а именно новый во всех отношениях образовательный процесс, который должен дать обучающимся максимальный объем знаний, компетентностей и возможностей для саморазвития, готовый дать ответы на вызовы цифрового общества, а будущим работодателям - компетентных, мобильных, конкурентоспособных специалистов. 
Вполне очевидно, что цифровая революция российского образования также в корне меняет методику, технологии преподавания.

На современном этапе развития общества новые цифровые технологии коренным образом меняют не только экономику общества, различные бизнес процессы, модели управления, но и весь жизненный уклад человека.

По мнению многих авторов, использование цифровых технологий открывает новые возможности для экономического развития, социальной интеграции труда, образования, хобби и отдыха, мобилизуя на это весь человеческий капитал.

Для адаптации к цифровому инфраструктурно-изменяющемуся миру необходимы различные виды цифровых знаний. Эксперты выделяют следующие основные движущие силы, обусловливающие необходимость развивать навыки труда и цифровые знания будущих специалистов всех отраслей хозяйствования страны: растущая глобализация; увеличение продолжительности человеческой жизни; автоматизация рабочих мест; быстрое распространение данных и вычислительных мощностей; распространение средств коммуникации и средств массовой информации с использованием ИКТ; беспрецедентная реорганизация работы благодаря новым технологиям и социальным медиа, которые значительно расширяют возможности сотрудничества на международном уровне [12].

Относительно области развития профессионального образования, по мнению основателей нового тренда российского образования, цифровизация приведет к кардинальному изменению рынка труда, появлению новых компетенций, улучшению кооперации, повышению ответственности граждан, их способности принимать самостоятельные обоснованные и максимально эффективные решения и т.д. [15].

В скором будущем, по мнению аналитиков, школьное образование ожидают кардинальные изменения: Единый государственный экзамен (ЕГЭ) сменится на портфолио на основе распределенного реестра; тьютор - на маршрутизатор на основе искусственного интеллекта; тренинг - чат-бот; тестирование - компьютерные образовательные игровые модели; симуляторы заменят дорогостоящие и сложные по организационной структуре комплексы для тренировки навыков; разработку рабочих программ произведут голосовые ассистенты учителя и т.д. Нам остается только предположить, что в профессиональном образовании данный спектр изменений, решаемых с помощью цифровых технологий, будет значительно расширен.
Надо подчеркнуть, что цель цифровизации профессионального образования состоит в обеспечении широкой доступности к информационно-цифровым ресурсам и использовании цифровых технологий в образовательном процессе и воспитании. С переходом на «цифру» образовательная организация и преподавательский состав должны получить более комфортные, удобные и экономичные средства деятельности.

Мы согласны с тем, что цифровые технологии в образовании - это способ организации современной образовательной среды, основанный на цифровых технологиях.

Как отмечают эксперты в области образования, широкое и быстрое развитие цифровых технологий в этой сфере диктуется рядом проблем:

- цифровые технологии в образовании поддерживаются на государственном уровне и широкой общественностью;

- это инструмент эффективной доставки информации и знаний студентов;

- это инструмент создания учебных материалов;

- это инструмент эффективного способа преподавания;

- это средство построения новой образовательной среды [14].

Анализируя научную, методическую литературу, мы отмечаем появление новых цифровых технологий, которые обладают большим педагогическим потенциалом.

В последнее время самыми распространенными можно считать облачные технологии, которые позволяют хранить огромное количество информации и имеют удобный сетевой доступ к информационным ресурсам.

Также следует отдельно отметить, такие образовательные технологии, получившие широкое распространение, как онлайн-курсы, предоставляемые многими вузами для всех обучающихся. Данные дистанционные курсы помогают студентам обучаться в любой удобной для них форме, в удобное для них время и являются средством получения качественного обучения по любой, нужной и интересной для конкретного студента тематике по избранному направлению подготовки.

Российские массовые онлайн-курсы ведущих вузов размещены на образовательных платформах «Открытое образование», «Одно окно» (online.edu.ru), We.Study и др.

Указанные платформы предоставляют возможность зарегистрироваться любому желающему на эти курсы и обучаться, затем получить сертификат и предъявить в свой вуз для перезачета по соответствующей дисциплине. Инициатором этого проекта является «Открытое об- 
разование», предлагающее своим пользователям более 250 учебных курсов по разным дисциплинам [24].

Онлайн-обучение в цифровой образовательной среде следует рассмотреть в двух формах обучения: синхронное и асинхронное. Синхронное онлайн-обучение предполагает электронное взаимодействие обучающегося и преподавателя в конкретное указанное время. И, наоборот, в асинхронном обучении преподаватель выкладывает в Интернет теоретические материалы и различные практические задания по курсу, а обучающиеся работают с выложенной информацией в любое удобное для них время. Мы в своей практике используем «смешанное обучение», которое предполагает «совмещение реального обучения» лицом к лицу с преподавателем в аудитории и интерактивными возможностями.

Также следует отметить, что не теряет свою востребованность обучение с помощью мобильных приложений, позволяющее использовать учебную информацию через персональные цифровые устройства (смартфоны, планшеты и т.д.). На практике такая технология широко используется при онлайн-обучении.

В образовательной деятельности важную дидактическую цель должна иметь технология «Игрофикация (геймификация)» - обучение в игре. В ней применяются технологии, которые используются в знакомых нам видеоиграх. Одним из вариантов геймификации являются веб-квесты. Эта технология позволяет использовать и интегрировать ресурсы Интернет и новые технологии в учебный процесс и эффективно формировать с их помощью общую и профессиональную компетенции обучающихся, также такая технология позволяет организовать научно-исследовательскую и проектную деятельность студентов. Использование технологии геймификации позволяет овладевать новыми знаниями и компетенциями в увлекательной, творческой, активной среде.

Следует отметить, что использование указанных технологий позволяет педагогам решать такие дидактические задачи, как повышение мотивации, качества обучения; достижение ситуации успеха в обучении; формирование информационной культуры, компетенций; проявление интереса к обучению; решение творческих задач; активизация учебной деятельности.

Процесс цифровизации образования предусматривает такие перспективные инновационные технологии, как искусственный интеллект, блокчейн и виртуальная реальность, которые позволяют формировать у обучающихся широкий комплекс социальных компетенций, необходимых в условиях цифрового общества.

Искусственный интеллект - это технология, которая используется при решении интеллектуальных задач, и все ее разработки направлены на создание программ для распознавания образов, систем для выполнения творческих функций, которые традиционно считаются прерогативой человека. В образовании применяется компьютерная обучающая программа, которая усиливает интерактивность; и искусственный интеллект будет контролировать образовательный процесс от начала до конца.

Искусственный интеллект в профессиональную цифровую образовательную среду можно интегрировать разными путями, например:

- он может быть репетитором-тьютором. На практике уже существуют различные приложения, которые дают многие ответы на непонятные вопросы тем. Искусственный интеллект сможет контролировать, проверять, проанализировать работы студентов, указать ошибки, определить существующие пробелы, проблемы в учении, далее создать индивидуальные образовательные траектории;

- может автоматизировать оценку знаний и уровень компетенций. С помощью заданных критериев, шкал может проверять промежуточную и итоговую оценку знаний обучающихся и определить уровни сформированности компетенций по той или иной дисциплине;

- может анализировать поведение обучающихся. С помощью систем можно распознавать и оценивать, как студенты воспринимают тот или иной материал, это даст преподавателю определить индивидуальный темп усвоения тем для дифференциации обучения. С помощью искусственного интеллекта можно будет также проанализировать адаптацию студентов к обучению, причины прогулов, психологическое, эмоциональное, физическое состояние обучающихся.

Блокчейн технология, обеспечивающая хранение данных, обладающая распределенным ресурсом, как мы знаем, обычно используется в финансовой сфере. Она гарантирует безопасность хранения данных в цифровом формате, а также осуществляет контроль за их изменением.

В системе образования блокчейн может решить такие актуальные вопросы как аккредитация, цифровая сертификация, оплата студенческих платежей, хранение документации.

Технологии виртуальной реальности - созданный техническими средствами мир, передаваемый человеку через его ощущения: зрение, слух, осязание и другие. Существуют следующие виды систем виртуальной реальности - это технические устройства и программное обеспечение, создающие для человека иллюзию присутствия в этом искусственном мире и в ряде случаев по- 
зволяющие манипулировать его объектами:

- обычная (классическая) виртуальная реальность (VirtualReality - VR), где обучающиеся взаимодействуют или погружаются в виртуальный мир с помощью компьютерной программы;

- дополненная или компьютероопосредованная реальность (AmendedReality - AR), где осуществляется накладка на генерируемую компьютером информацию сверху на изображения реального мира;

- смешанная реальность (MixedReality - MR), где реальный мир связан с виртуальным, и они объединены между собой.

Технология MR может использоваться для решения различных задач и является универсальной. Например, у преподавателей и обучающихся есть возможность создания и использования виртуальных лабораторий для изучения окружающей действительности, формирования умений и отработки навыков, для демонстрации их освоения и оценивания с помощью искусственного интеллекта и т.д.

Эти технологии широко используются для виртуальных путешествий, ознакомления с другими культурами и применяются при изучении иностранного языка. Они облегчают и упрощают совместную деятельность людей, которые находятся на расстоянии. Например, виртуальная реальность дает возможность проведения видеоконференций, создавать совместные проекты, чувствовать себя так же, как в реальном мире.

При изучении естественнонаучных дисциплин студенты при помощи виртуальной реальности могут оказаться в виртуальных лабораториях и проводить различные эксперименты, научные опыты, осуществлять взаимодействия с различными объектами и вести наблюдение за различными процессами, происходящими в природе.

С помощью виртуальной реальности можно осуществлять проектирование трехмерных объектов. На- пример, обучение авиапилотов, обучение медицинским навыкам осуществляется с помощью приложения MR.

Цифровизация образования не только меняет содержание преподаваемых дисциплин, но и подачу информации, это не только презентации или видео, это уже прямые подключения к информационным сетям, базам данных, форумам. Когда проводятся практические занятия, возможно использование социальных сетей, что и доказала практика дистанционного обучения последних дней. В цифровом мире педагоги должны уметь анализировать, применять различные информационные ресурсы, разрабатывать дистанционные курсы и создавать эффективные учебные среды, в том числе интернет-мессенджер WhatsApp.

Следует подчеркнуть, что актуальными в обучении становятся электронные издания и многие издательства, специализирующиеся на издании учебной и методической литературы, переходят на электронные версии учебников, что очень удобно, например, в дистанционном обучении.

В настоящее время в условиях пандемии, связанной с распространением коронавирусной инфекции в мире, студенты и преподаватели получили неограниченные возможности для развития своего образовательного пространства и его совместного использования. Но, наша система образования показала местами недостаточную подготовленность к такой перестройке, и, как показала практика, несмотря на огромный потенциал цифровых технологий, который востребован в образовании, он используется не всеми и не в полной мере, это обусловлено с недостаточной цифровой грамотностью преподавателей и материально-техническим оснащением в области IT образовательных организаций.

Доступ и использование цифровых технологий должно являться актуальной задачей цифровой трансформации образования в каждом учреждении, реализующем основные образовательные программы.

\section{ЛИТЕРАТУРА}

1. Цифровая Россия: новая реальность Государственная Программа Российской Федерации «Развитие образования на 2013-2020 г.г.» URL:http://new.volsu. ru/upload/medialibrary/809/Проект_Развитие образования 2013-2020.pdf

2. Программа «Цифровая экономика Российской Федерации» утверждена распоряжением Правительства Российской Федерации от 28.07.2017 № 1632-р.

3. Приоритетный проект в области образования «Современная цифровая образовательная среда в Российской Федерации» [Электронный ресурс]. Режим доступа: http://neorusedu.ru (дата обращения: 25.05.2020).

4. Свободная энциклопедия «Викисловарь» [Электронный ресурс]. - Режим доступа: https://iktionary.org/wiki/цифровизация\#Семантические свойства. ru.

5. Баева Л.В. Электронная культура: опыт философского анализа // Вопросы философии. 2013. № 5. С. 75-84.

6. Богданова Н.В., Пузанкова Л.В. Особенности применения мультимедийных технологий в преподавании дисциплин информатики с учетом цифровизации образования // Информатика и прикладная математика: межвузовский сборник научных трудов. 2019. № 25. С. 29-34. 
7. Вартанова Е.Л. Индустрия российских медиа : цифровое будущее / Е.Л. Вартанова, А.В. Вырковский, С.С. Смирнов, М.И. Макеенко. - М.: МедиаМир, 2017. $-160 \mathrm{c}$.

8. Гнатышина Е.В., Саламатов А.А. Цифровизация и формирование цифровой культуры: социальные и образовательные аспекты // Вестник Челябинского государственного педагогического университета. Педагогические науки. 2017. № 8. С. 19-24.

9. Гусакова Е.М., Гусакова Т.А. Реализация активных методов преподавания математики в условиях цифровизации образования // Педагогический журнал. 2019. Т. 9. № 1-1. С. 610-619.

10. Горбачев В.И., Язвенко М.Д. Технология реализации учебной дисциплины «прикладная математика» В содержании компетентностного подхода СПо // Ученые записки Брянского государственного университета. 2018. № 1 (9). С. 7-11.

11. Дьякова Е.А., Сечкарева Г.Г. Цифровизация образования как основа подготовки учителя XXI века: проблемы и решения // Вестник Армавирского государственного педагогического университета. 2019. № 2. С. 24-36. URL: https://cyberleninka.ru/article/n/tsifrovizatsiya-obrazovaniya-kak-osnovapodgotovki-uchitelya-xxi-veka-problemy-i-resheniya.

12. Клейменова Е.В. Педагогические условия реализации технологии вариативного обучения /Е.В. Клейменова // Вопросы современной науки и практики. Университет им. В.И. Вернадского. - Тамбов: Издательско-полиграфический центр ТГТУ, 2009. - № 11(25). - С. 52-57.

13. Кудлаев, М.С. Процесс цифровизации образования в России / М.С. Кудлаев. - Текст : непосредственный // Молодой ученый. — 2018 . — № 31 (217). —C. 3-7. — URL: https://moluch.ru/archive/217/52242/ (дата обращения: 26.05.2020).

14. Кузьминов Я. Главный тренд российского образования — цифровизация. URL: www.ug.ru (дата обращения: 12.05.2019).

15. Марей А. Цифровизация как изменение парадигмы [Электронный ресурс]. - Режим доступа: ttps://www.bcg.com/ru/about/bcgeview/digitalization.

16. Мультимедийная журналистика. М.: ВШЭ, 2017. 413 с.

17. Николенко Д.В., Болычева Я.К. Дистанционные образовательные технологии как средство повышения эффективности учебного процесса в СПо при изучении физико - математических дисциплин // Сборник статей Международной научно-практической конференции «Новая наука: история становления, современное состояние, перспективы развития». Уфа: Омега сайнс, 2020. С. 5-7.

18. Никулина Т.В. Информатизация и цифровизация образования: понятия, технологии, управление /Т.В. Никулина, В.Б. Стариченко // Педагогическое образование в России. - 2018. - № 8. - С. 107-113.

19. Уваров А.Ю. Технологии виртуальной реальности в образовании // Наука и школа.- 2018.- №4.-С.108-117.

20. Сапожкова Н.А. Модель формирования готовности будущих учителей математики к развитию системного мышлению в условиях цифровизации образования // Перспективы науки. 2019. № 7 (118). С. 194-196.

21. Смирнова Н.В. Организация работы преподавателя математики в системе СПО с применением современных образовательных технологий // 0бразование и наука в России и за рубежом. 2019. № 2 (50). С. 532-534.

22. Сучкова Н.В. Современные методы обучения математике студентов СПО на основе информационных технологий // Сборник статей по материалам LIX международной научно-практической конференции «Инновационные подходы в современной науке». М.: Интернаука, 2019. С. 55-58

23. Третьяков В.С., Ларионова В.А. Открытые онлайн-курсы как инструмент модернизации образовательной деятельности в вузе // Высшее образование в России.2016. № 7 (203). С. 55-66.

24. Аналитический отчет экспертной группы Digital. 000 «Мак-Кинзи и Компания СиАйəс», 2017. Available at: www.mckinsey.ru

25. Kiron D., Prentice P.K., Ferguson R.B. Raising the bar with analytics // MIT Sloan Management Review. 2014. Vol. 55.P. $29-33$.

26. Schwab K. The Fourth Industrial Revolution. World Econom- [15] ic Forum, Geneva, Switzerland, 2016. 172 p. URL: https:// luminariaz.files.wordpress. com/2017/11/the-fourth-in-dustrial-revolution-2016-21.pdf (дата обращения: 25.05.2020).

() Егорова Елена Михайловна (Elena-sakha@mail.ru).

Журнал «Современная наука: актуальные проблемы теории и практики» 